\title{
Avaliação do comportamento reológico de diferentes iogurtes comerciais
}

\author{
Rheological evaluation of different commercial yoghurts
}

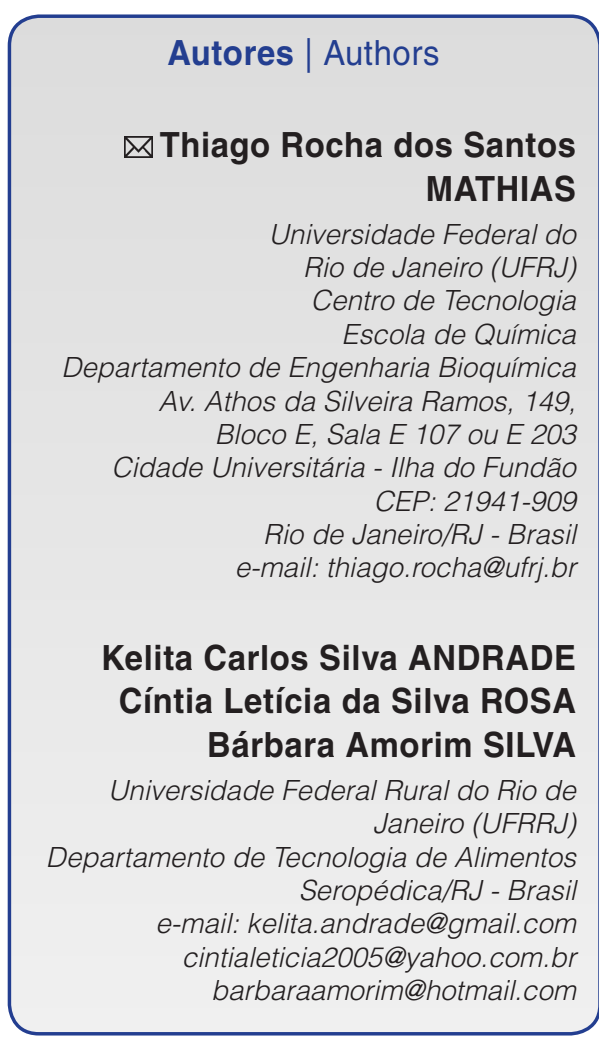

Autor Correspondente / Corresponding Author

Recebido / Received: 30/03/2011 Aprovado / Approved: 13/09/2012 Publicado / Published: mar./2013

\section{Resumo}

A consistência e a viscosidade do iogurte são uns dos principais fatores envolvidos na qualidade e aceitação do produto. Dessa forma, este trabalho apresenta um estudo de comparação reológica entre iogurtes comerciais do Rio de Janeiro, Brasil, em cujas formulações constam diferentes espessantes. Foram utilizadas três grandes marcas do mercado e, entre os espessantes utilizados, estão: goma guar, goma xantana, goma carragena, goma alfarroba e carboximetilcelulose. Previamente às análises reológicas, as amostras de iogurtes foram submetidas à determinação do $\mathrm{pH}$, da acidez (expressa em ácido láctico) e da umidade. As curvas de fluxo e de viscosidade foram obtidas em reômetro rotacional Thermo Haake Mars com geometria placa/placa (35 mm de diâmetro), com variação de taxa de cisalhamento entre 0,02 e $100 \mathrm{~s}^{-1}$ (curva ascendente), e 100 e 0,02 s-1 (curva descendente), em um tempo total de 20 minutos. Foi determinada a histerese como a área entre as curvas e ajustados os modelos de Bingham, Casson, Herschel-Bulkley e Ostwald de Waele. Foram realizados também testes de tixotropia, pela medição da viscosidade em função do tempo a uma taxa constante de $100 \mathrm{~s}^{-1}$, por 10 minutos. Estes foram ajustados pelo modelo de Weltman. Além disso, foram verificadas alterações no comportamento reológico em função da variação de temperatura $\left(4\right.$ a $\left.24^{\circ} \mathrm{C}\right)$, cujos resultados foram avaliados pela Equação de Arrhenius. Todas as amostras de iogurte analisadas apresentaram comportamento pseudoplástico e tixotrópico. Todos os modelos foram bem ajustados para as curvas de fluxo, exceto o modelo de Weltman, que não representou bem os testes de tixotropia.

Palavras-chave: logurte; Espessantes; Reologia; Viscosidade.

\section{Summary}

Yoghurt consistency and viscosity are two of the major factors involved in product quality and acceptance. Thus this paper presents a comparative study of the rheology of commercial yoghurts in Rio de Janeiro, Brazil, whose formulations included different thickeners. Three major market brands were used and the thickeners included guar gum, xanthan gum, carrageenan gum, locust bean gum and carboxymethylcellulose. Before the rheological tests, samples of the yoghurts were submitted to the determination of $\mathrm{pH}$, acidity (expressed as lactic acid) and moisture content. The flow and viscosity curves were obtained using a rotational Thermo Haake Mars rheometer with plate/plate geometry (diameter $35 \mathrm{~mm}$ ), varying the shear rate from 0.02 to $100 \mathrm{~s}^{-1}$ (rising curve) and from 100 to $0.02 \mathrm{~s}^{-1}$ (falling curve) in a total time of 20 minutes. Hysteresis was determined as the area between the curves and fitted to the models of Bingham, Casson, Herschel-Bulkley and the Power Law. Thixotropy tests were also carried out by measuring the viscosity versus time at a constant rate of $100 \mathrm{~s}^{-1}$ for 10 minutes. These were fitted to the Weltman model. Moreover, the changes in the rheological behaviour as a function of temperature $\left(4-24{ }^{\circ} \mathrm{C}\right)$ were observed, and the results evaluated using the Arrhenius equation. All the yoghurt samples showed pseudoplastic and thixotropic behaviour and all the models fitted the flow curves well, with the exception of the Weltman model, which did not represent the thixotropy tests well.

Key words: Yoghurt; Thickeners; Rheology; Viscosity. 


\section{Introdução}

O iogurte é um alimento funcional rico em proteínas, ácido fólico, vitamina $A$, vitaminas do complexo $B$ e sais minerais, cujo consumo traz diversos benefícios para a saúde (CHANDAN et al., 2006). É um produto obtido a partir da fermentação do leite pasteurizado com adição de bactérias lácticas tradicionais, como Streptococcus thermophilus e Lactobacillus bulgaricus (BRASIL, 2001).

Visto que a indústria de laticínios tem papel fundamental no mercado de alimentos funcionais (GONÇALVES e EBERLE, 2008), o consumo deste alimento tem tido aumentos consideráveis, em razão da busca por uma alimentação mais saudável e sadia. Existem vários tipos de iogurte, para alcançar o extenso mercado consumidor. Estes produtos podem variar de acordo com os ingredientes, a composição, o sabor, a consistência, a textura, o valor calórico, o processo de elaboração e a natureza do processo de pós-incubação (RASIC e KURMANN, 1978). A qualidade do produto final é de grande importância na sua aceitação e esta é influenciada principalmente por sua consistência e sua viscosidade.

A textura do produto e a propensão à sinérese (separação do soro) são umas das principais características que irão definir a qualidade do iogurte (LEE e LUCEY, 2010). Geralmente, para se aumentar a viscosidade do produto, a prática utilizada nas indústrias é o aumento do teor de sólidos pela adição de leite, ou soro de leite, em pó (TAMIME e ROBINSON, 1991). Porém, também podem ser adicionados espessantes com este fim, deixando uma textura mais firme, diminuindo a sinérese e aumentando a aceitabilidade do iogurte.

Diversos materiais poliméricos podem ser utilizados como espessantes e sua origem pode ser vegetal ou microbiana. Entre os polissacarídeos, estão o amido, a pectina, a carragenana, os alginatos, a goma xantana, a goma gelana e a goma arábica. Entre os materiais proteicos, estão os caseinatos e a gelatina (TONELI et al., 2005). Segundo Walstra et al. (2006) e Tamime e Robinson (1991), três dos espessantes mais utilizados são o amido, a pectina e a gelatina.

Muitos fatores podem afetar a reologia do iogurte, como o teor de sólidos, as temperaturas de tratamento térmico do leite e da fermentação, a pressão de homogeneização, dentre outros (COLLET e TADINI, 2004; PASEEPHOL et al., 2008). Assim, o objetivo dos estudos reológicos é verificar o comportamento estrutural dos alimentos frente aos possíveis processamentos, permitindo o dimensionamento correto de bombas, tubulações, trocadores de calor, operações de agitação e envase, sem afetar a qualidade do produto final (OLIVEIRA et al., 2008). Além destas, outras aplicações do estudo reológico encontram-se no controle de qualidade, na análise sensorial e em testes de tempo de prateleira (DRAKE, 2007).

Estudos reológicos geralmente envolvem relações entre taxa de cisalhamento e tensão de cisalhamento. Quando a relação é linear, o fluido é dito newtoniano e sua viscosidade é constante, independentemente da taxa ou tensão aplicadas. Entretanto, em muitos casos, essa relação é não linear e o fluido é classificado como não newtoniano. Estes fluidos podem ser pseudoplásticos, os quais apresentam diminuição da viscosidade conforme aumenta a taxa de cisalhamento aplicada (SCHRAMM, 2006). Além da dependência da taxa, fluidos pseudoplásticos podem ser tixotrópicos, dependentes também do tempo de cisalhamento. Neste caso, mesmo para taxas cisalhantes constantes, a viscosidade sofre uma redução em função do tempo. Curvas de fluxo de fluidos tixotrópicos apresentarão distinção entre as curvas de taxa crescente e de taxa decrescente, sendo este fenômeno conhecido como histerese. Modelos como os de Ostwald de Waele, Hershel-Bulkley e Casson, apesar de não levarem em consideração a dependência com o tempo, têm sido bem aplicados para descrever o comportamento reológico destes fluidos (OLIVEIRA et al., 2008; MULLINEUX e SIMMONS, 2007; TONELI et al., 2005).

O presente trabalho teve por objetivo estudar o comportamento reológico de três iogurtes comerciais que utilizam diferentes espessantes em seus processos de produção. Foi verificada a influência destes espessantes na viscosidade em função da taxa e do tempo de cisalhamento, aplicando os modelos de Bingham, Casson, Herschel-Bulkley e Ostwald de Waele para as curvas de fluxo, e o modelo de Weltman para os testes de tixotropia.

\section{Material e métodos}

Foram utilizados para os testes reológicos três iogurtes comerciais adquiridos no mercado local do Rio de Janeiro-RJ. Foram codificados da seguinte maneira, com seus respectivos espessantes: IC1 (Goma alfarroba); IC2 (Goma xantana e Goma guar); IC3 (Carboximetilcelulose, Goma carragena e Goma xantana). Os valores de composição centesimal dos iogurtes são indicados na Tabela 1, conforme indicação nos rótulos. Segundo todos os fabricantes, foi utilizado como inóculo

Tabela 1. Composição centesimal.

\begin{tabular}{|c|c|c|c|}
\hline \multirow{2}{*}{ Componente } & \multicolumn{3}{|c|}{ Amostras } \\
\hline & IC1 & IC2 & IC3 \\
\hline Carboidratos (\%) & 15,0 & 14,5 & 13,5 \\
\hline Proteínas (\%) & 2,5 & 2,3 & 2,3 \\
\hline Gorduras Totais (\%) & 2,5 & 1,0 & 2,3 \\
\hline
\end{tabular}


'fermento lácteo', sem especificação de culturas ou quantidade utilizada.

As amostras de iogurtes foram submetidas a determinações analíticas, com medição dos valores de $\mathrm{pH}$ (por medição direta em pHmetro), da acidez expressa em ácido láctico (por titulação com $\mathrm{NaOH} \mathrm{0,1} \mathrm{M)} \mathrm{e} \mathrm{da}$ umidade (por secagem em estufa a $105^{\circ} \mathrm{C}$ ).

As análises reológicas foram realizadas em triplicata, em reômetro rotacional Thermo Haake MARS (Karlsruhe, Alemanha), equipado com geometria placa/ placa, com $35 \mathrm{~mm}$ de diâmetro, disponibilizado na EMBRAPA Agroindústria de Alimentos - Rio de Janeiro. Foi utilizado um gap (espaço delimitado entre as placas) de $1 \mathrm{~mm}$ e um volume de amostra de $1 \mathrm{~mL}$, conforme indicado pelo software do referido equipamento. 0 reômetro possui controlador de temperatura Haake Mars Controller do tipo Peltier, cujo valor foi ajustado a $8{ }^{\circ} \mathrm{C}$ (GONÇALVEZ et al., 2005; SODINI et al., 2005), exceto quando as análises foram realizadas em função da temperatura, cuja faixa variou entre 4 e $24^{\circ} \mathrm{C}$.

As curvas de fluxo e de viscosidade foram obtidas pela determinação da tensão e da viscosidade em função da taxa de cisalhamento, respectivamente. A taxa variou entre 0,02 e $100 \mathrm{~s}^{-1}$ (curva ascendente) e entre 100 e 0,02 s-1 (curva descendente). O tempo total de análise (curvas ascendente e descendente) foi de 20 min., sendo coletados 80 pontos neste intervalo. Os resultados foram ajustados aos modelos de Bingham, Casson, Herschel-Bulkley e Ostwald de Waele (STEFFE, 1996), tanto para as curvas de fluxo como para as curvas de viscosidade.

Os testes de tixotropia foram realizados pela aplicação de uma taxa de cisalhamento constante de 100 $\mathrm{s}^{-1}$ e a determinação da viscosidade em função de um tempo de 10 min., com coleta de 40 pontos. Os resultados deste teste foram submetidos ao ajuste do modelo de Weltman, dependente do tempo (GONÇALVEZ et al., 2005; STEFFE, 1996).

O efeito da temperatura foi avaliado pela medição da viscosidade a uma taxa de cisalhamento constante de $100 \mathrm{~s}^{-1}$, com temperatura variando de 4 a $24^{\circ} \mathrm{C}$, em um intervalo de tempo de 25 minutos $\left(\Delta \mathrm{T}=0,8^{\circ} \mathrm{C} / \mathrm{min}\right)$, coletando-se 100 pontos no total. As curvas de viscosidade em função da temperatura foram ajustadas a uma equação do tipo Arrhenius (STEFFE, 1996).

Inicialmente, todas as amostras de iogurte foram igualmente submetidas à agitação em mixer por um minuto, na velocidade de rotação de 150 RPM e, em seguida, permaneceram em repouso sob refrigeração $\left(10{ }^{\circ} \mathrm{C}\right.$ ) por dez minutos (PASEEPHOL et al., 2008; SODINI et al., 2005). Para todas as análises, o reômetro foi acoplado ao software Haake RheoWin 3 para obtenção das curvas, ajuste dos modelos e cálculo da histerese.

A Tabela 2 apresenta os modelos reológicos ajustados (STEFFE, 1996).

\section{Resultados e discussão}

Os resultados das determinações analíticas para cada amostra de iogurte comercial estão dispostos na Tabela 3.

As Figuras 1 e 2 mostram as curvas de fluxo e de viscosidade para as três marcas de iogurte comercial, respectivamente.

A amostra IC1 apresentou os maiores valores de viscosidade (viscosidade média 286,3 mPas) em toda a faixa de taxa de cisalhamento analisada. Em seguida,

Tabela 2. Modelos reológicos.

$\begin{array}{lcc}\text { Mingham } & \text { Viscosidade } & \text { Tensão } \\ \text { Casson } & \eta=\eta_{p}+\tau_{0} / \dot{\gamma} & \tau=\tau_{0} \dot{\gamma} \\ \text { Ostwald de Weale } & \eta=\sqrt[n]{\left(\tau_{0} / \dot{\gamma}\right)^{n}+\left(\eta_{p}\right)^{n}} & \tau^{0,5}=\tau_{0}^{0,5}+K(\dot{\gamma})^{0,5} \\ \text { Herschel-Bulkley } & \eta=K \dot{\gamma}^{n-1} & \tau=K \dot{\gamma}^{n} \\ \text { Weltman } & \eta=\tau_{0} / \dot{\gamma}+K \dot{\gamma}^{n-1} & \tau=\dot{\gamma}^{n} \\ \text { Arrhenius } & - & \tau=A-B . \log (\mathrm{t})\end{array}$

em que: $\eta=$ viscosidade (Pa.s); $\mathrm{K}=$ índice de consistência (Pa. $\left.\mathrm{s}^{n}\right) ; n=$ índice de comportamento (adimensional); $\tau=$ tensão de cisalhamento $(\mathrm{Pa}) ; \dot{\gamma}=$ taxa de deformação $\left(\mathrm{s}^{-1}\right) ; \eta_{p=}$ viscosidade plástica; $\tau_{0}=$ limite de escoamento; $A=$ parâmetro reológico semelhante a $\tau_{0} ; B=$ parâmetro reológico que mede a taxa de quebra da estrutura; $\mathrm{t}=$ tempo; $\mathrm{k}=$ parâmetro de ajuste; $\mathrm{E}=$ energia de ativação para viscosidade $(\mathrm{J} / \mathrm{kg} . \mathrm{mol} . \mathrm{K})$; $R=$ constante universal dos gases $(1,987 \mathrm{cal} / \mathrm{g} \cdot \mathrm{mol} . \mathrm{k}) ; \mathrm{T}=$ temperatura absoluta $(\mathrm{K})$. 


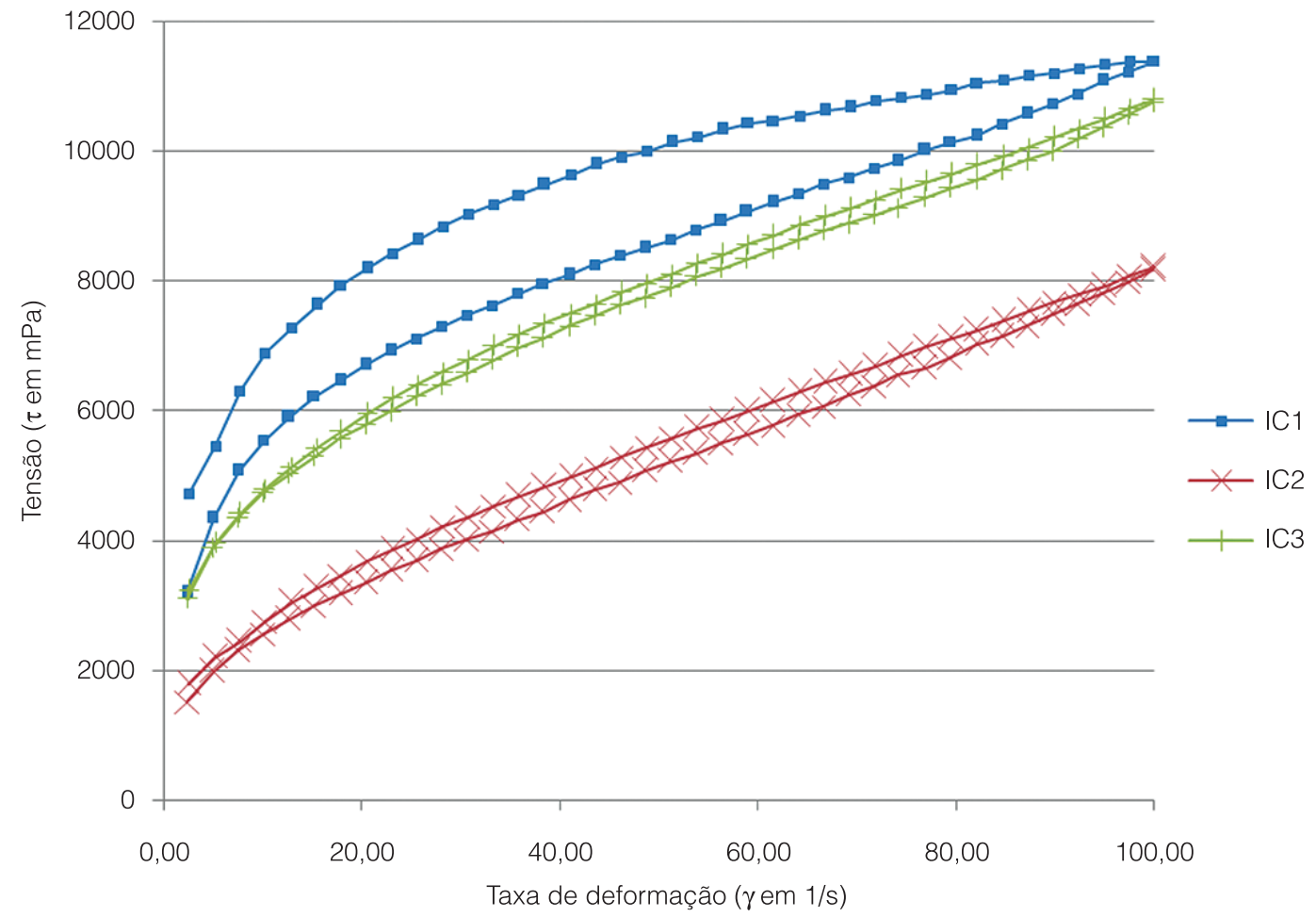

Figura 1. Curvas de fluxo das amostras de iogurte. [IC1 (Goma alfarroba), IC2 (Goma xantana e Goma guar), IC3 (Carboximetilcelulose, Goma carragena e Goma xantana)].

Tabela 3. Determinações analíticas das amostras de iogurtes comerciais.

\begin{tabular}{cccc}
\hline Amostra & $\mathbf{p H}$ & Acidez (\%) & Umidade (\%) \\
IC1 & 4,11 & 0,70 & 78 \\
IC2 & 4,30 & 0,68 & 81 \\
IC3 & 4,22 & 0,63 & 79 \\
\hline
\end{tabular}

os maiores valores obtidos foram para a amostra IC3 (viscosidade média 236,3) e, por último, a amostra IC2 (viscosidade média 144,7). Estes resultados são coerentes com os cálculos dos teores de umidade para as amostras. A amostra IC1 (mais viscosa) apresenta o maior teor de extrato sólido total (22\%), em comparação à amostra IC2 (menos viscosa), que apresenta o menor teor de sólidos não voláteis (19\%).

Os valores de $\mathrm{pH}$ e acidez, expressa em ácido láctico, foram bastante semelhantes para as três amostras. Segundo Robinson et al. (2006), valores de pH menores do que 4 podem promover a sinérese do iogurte, em função da excessiva repulsão de cargas, alterando suas características reológicas. Tal fato não foi observado nos iogurtes comerciais avaliados, podendo-se concluir que, neste caso, o pH e a acidez não promoveram diferenças no comportamento reológico.
Os teores de carboidratos e proteínas dos três iogurtes comerciais avaliados são bastante semelhantes, destacando-se diferença apenas para o teor de gorduras totais, sendo este menor para a amostra IC2, quando comparada às amostras IC1 e IC3. Coerentemente, os menores valores de viscosidade foram obtidos para a amostra IC2, visto que o teor de gordura é um fator de influência na reologia do produto (COLLET e TADINI, 2004; PASEEPHOL et al., 2008).

Segundo Teles e Flôres (2007), a adição do espessante goma xantana apresenta maior efeito sobre a viscosidade do que a goma guar. Já entre as gomas carragena e guar, a primeira apresenta alto poder espessante, enquanto a segunda pode ser utilizada para aumentar o poder geleificante de outros espessantes (FiB, 2010). Dessa maneira, a despeito das concentrações utilizadas, a amostra IC3 (Carboximetilcelulose, Goma carragena e Goma xantana) apresentou maiores valores de viscosidade que a amostra IC2 (Goma xantana e Goma guar) (Figura 2).

Note-se que, independentemente dos espessantes utilizados, todas as amostras de iogurte analisadas apresentaram comportamento de fluido não newtoniano e pseudoplástico, uma vez que houve diminuição da viscosidade em função do aumento da taxa de cisalhamento aplicada (SCHRAMM, 2006). Segundo Horne (1998) e Lucey (2002), isso pode ocorrer em razão 


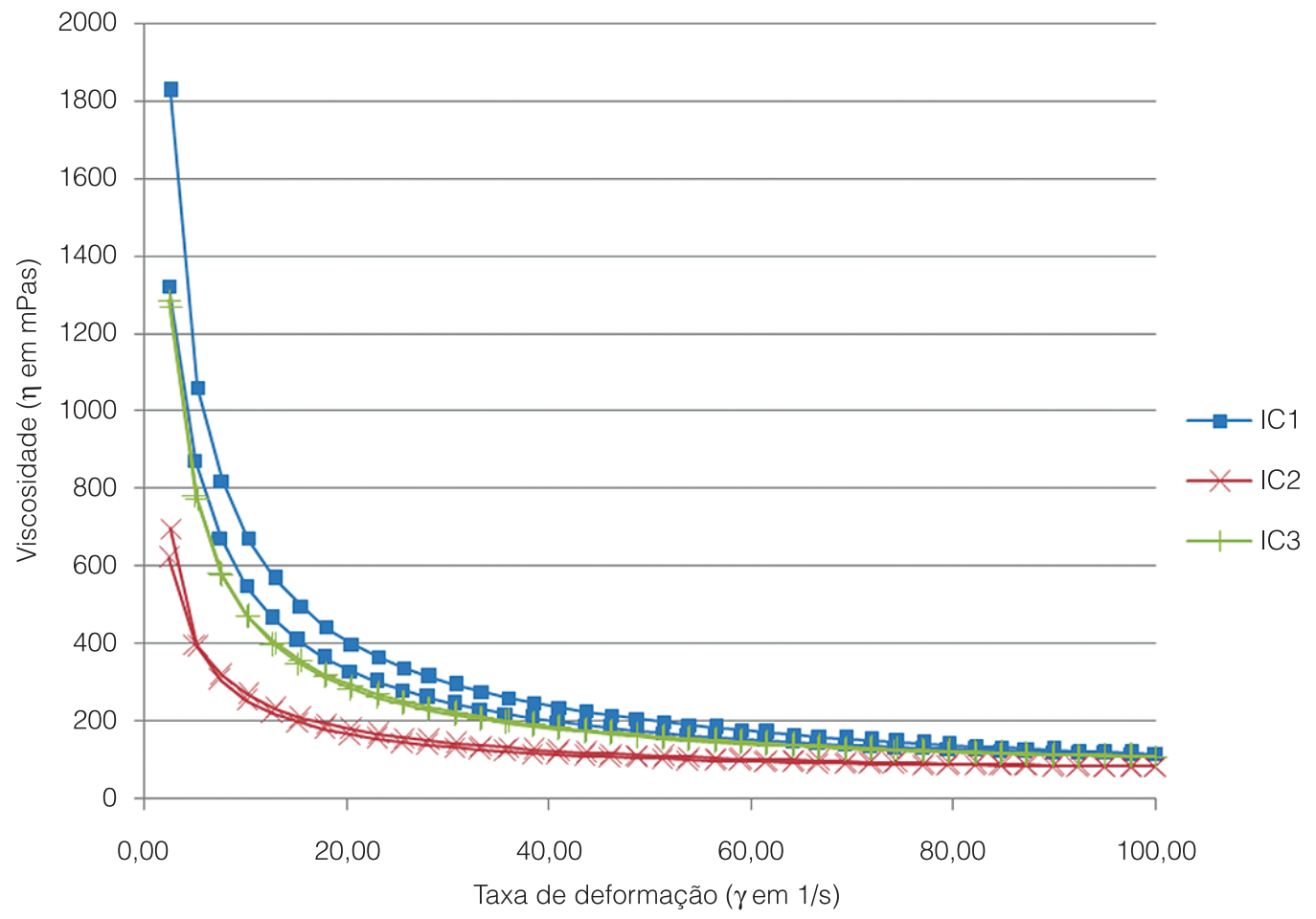

Figura 2. Curvas de viscosidade das amostras de iogurte. [IC1 (Goma alfarroba), IC2 (Goma xantana e Goma guar), IC3 (Carboximetilcelulose, Goma carragena e Goma xantana)].

do enfraquecimento das fracas interações existentes entre as moléculas do produto e da diminuição da energia de interação entre estas. Diversos estudos confirmam o iogurte como fluido pseudoplástico (GONÇALVEZ et al., 2005; GOMES e PENNA, 2009; TELES e FLÔRES, 2007; PASEEPHOL et al., 2008).

Conforme observado nas Figuras 1 e 2, todas as amostras também apresentaram características tixotrópicas, em função das diferenças de tensão e viscosidade entre as curvas de taxa ascendente e descendente. Este fenômeno, conhecido por histerese, é resultado da quebra do gel e pode ser quantificado como a área entre as curvas de fluxo. Quanto maior a área compreendida entre as curvas, maior o efeito tixotrópico (HOLDSWORTH, 1993). Os valores determinados pelo software são apresentados na Tabela 4.

Observa-se que a amostra IC1, com espessante goma alfarroba e maiores valores de viscosidade, foi a que apresentou característica tixotrópica mais evidente, representada pela maior área de histerese calculada. As demais amostras IC2 e IC3 apresentaram valor de histerese em uma ordem de grandeza menor. Tal fato pode ser explicado pelos maiores valores de viscosidade obtidos para a amostra IC1, o que permite uma redução relativa desta grandeza mais significativa durante o cisalhamento. Dentre as amostras IC2 e IC3, o menor valor de histerese foi obtido para o segundo, que possui maior
Tabela 4. Histerese das amostras de iogurte comerciais.

\begin{tabular}{cc} 
Amostra & Histerese (Pa/s) \\
IC1 & 112,0 \\
IC2 & 27,2 \\
IC3 & 16,0 \\
\hline
\end{tabular}

teor de gordura que o primeiro, indicando o potencial caráter protetor deste componente à reologia do produto.

Os quatro modelos reológicos (Tabela 2) foram ajustados às curvas ascendentes de fluxo e de viscosidade das amostras de iogurte, cujos valores dos coeficientes de regressão $r$ são apresentados nas Tabelas 5 e 6, respectivamente.

Ao realizar uma análise de variância no nível de 5\% de significância, com a finalidade de avaliar os valores de $r$ para as curvas de fluxo e de viscosidade separadamente (Tabelas 5 e 6), verifica-se que, para as curvas de fluxo, os coeficientes apresentam diferenças significativas $(p<0,05)$, indicando que o tipo e a concentração de espessante utilizados acarretam alterações nas características reológicas do iogurte. Já as curvas de viscosidade são bem ajustadas por todos os modelos, sem diferenças significativas $(p>0,05)$.

Em praticamente todos os iogurtes analisados, os resultados mostraram-se melhor ajustados ao modelo de 
Avaliação do comportamento reológico de diferentes iogurtes comerciais

MATHIAS, T. R. S. et al.

Herschel-Bulkley $(r>0,99)$. Em contrapartida, o modelo de Bingham apresentou a pior adequação às curvas de fluxo e viscosidade, o que confirma a relação não linear entre a tensão e a taxa de cisalhamento, classificando os iogurtes analisados como fluidos não newtonianos (STEFFE, 1996).

O modelo de Ostwald-de-Waele, assim como o de Herschel-Bulkley, considera a relação não linear entre a tensão e a taxa de cisalhamento. Porém, este modelo não leva em consideração a tensão limite de escoamento $\left(\tau_{0}\right)$ (TONELI et al., 2005). Em função da semelhança entre os modelos, com exceção de um coeficiente linear na equação matemática, ambos apresentaram ajustes com valores de $r>0,99$. No entanto, a utilização do modelo de Ostwald-de-Waele leva à perda de uma importante informação para o processamento de iogurte $\left(\tau_{0}\right)$ (STEFFE, 1996).

A Tabela 7 apresenta os parâmetros da equação de Herschel-Bulkley ajustada às curvas de fluxo das diferentes amostras de iogurte.

Pode ser observado que todos os valores referentes ao índice de escoamento (n) são menores que um, em concordância com dados da literatura, corroborando para a classificação dos fluidos analisados como não

Tabela 5. Valores de $r$ para os modelos ajustados às curvas de fluxo.

\begin{tabular}{lccc}
\multicolumn{1}{c}{ Modelo } & \multicolumn{3}{c}{$\boldsymbol{r}$ (Curvas de fluxo) } \\
& IC1 & IC2 & IC3 \\
Bingham & 0,9263 & 0,9944 & 0,9844 \\
Ostwald Weale & 0,9962 & 0,9965 & 0,9972 \\
Casson & 0,9937 & 0,9997 & 0,9978 \\
Herschel-Bulkley & 0,9993 & 0,9997 & 0,9995 \\
\hline
\end{tabular}

newtonianos pseudoplásticos (GONÇALVEZ et al., 2005; TELES e FLÔRES, 2007).

De forma coerente com os resultados obtidos para a viscosidade, o maior índice de consistência $(K)$ foi calculado para a amostra IC1, seguida pelas amostras IC3 e IC2, nesta ordem. O maior valor para a tensão limite de escoamento $\left(\tau_{0}\right)$ foi bastante elevado em relação aos demais, registrado para a amostra IC1.

Diversos trabalhos na literatura estudaram o comportamento reológico de diferentes formulações de iogurte, obtendo como resultados para o limite de escoamento $\left(\tau_{0}\right)$ valores entre 1,1 e 10,1 Pa, dependente do teor de sólidos, do tipo de espessante, do tipo de cultura starter (produtora ou não de exopolissacarídeos) e da presença de prebióticos (PASEEPHOL et al., 2008; TELES e FLÔRES, 2007; SODINI et al., 2005; GONÇALVEZ et al., 2005).

A análise da variação da viscosidade em função do tempo a uma taxa de cisalhamento constante também permitiu confirmar as características tixotrópicas das diferentes amostras de iogurte (Figura 3). Em conformidade com os dados apresentados na literatura, todas as amostras de iogurte apresentaram redução de viscosidade em função do tempo (MULLINEUX e SIMMONS, 2007; CUNHA NETO et al., 2005; GONÇALVEZ et al., 2005).

Tabela 6. Valores de $r$ para os modelos ajustados às curvas de viscosidade.

\begin{tabular}{lccc}
\multicolumn{1}{c}{ Modelo } & \multicolumn{3}{c}{$\boldsymbol{r}$ (Curvas de viscosidade) } \\
& IC1 & IC2 & IC3 \\
Bingham & 0,9898 & 0,9927 & 0,9911 \\
Ostwald Weale & 0,9997 & 0,9960 & 0,9976 \\
Casson & 0,9988 & 0,9996 & 0,9982 \\
Herschel-Bulkley & $\mathbf{0 , 9 9 9 7}$ & 0,9999 & 0,9999 \\
\hline
\end{tabular}
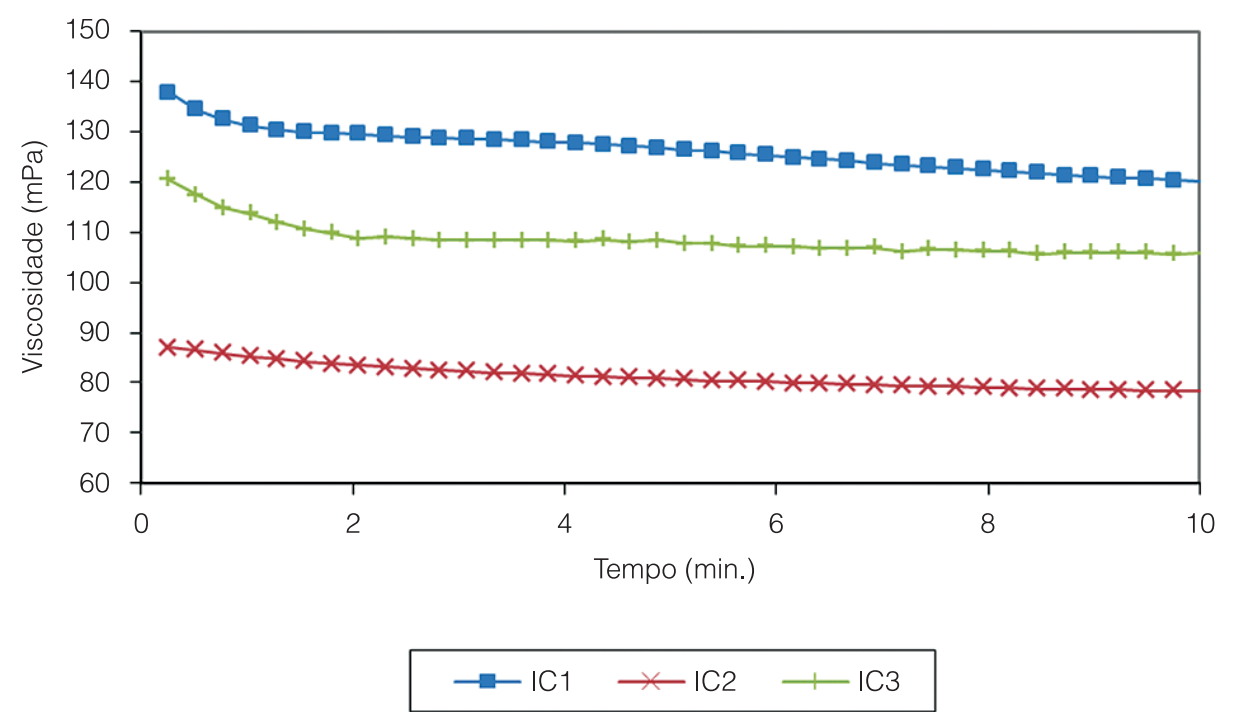

Figura 3. Teste de tixotropia das amostras de iogurte comercial. [IC1 (Goma alfarroba), IC2 (Goma xantana e Goma guar), IC3 (Carboximetilcelulose, Goma carragena e Goma xantana)]. 
Avaliação do comportamento reológico de diferentes iogurtes comerciais

MATHIAS, T. R. S. et al.

Verifica-se na Figura 3 que o maior valor de viscosidade é para a amostra IC1, seguido das amostras IC3 e IC2, nesta sequência, em toda a faixa de tempo avaliada, corroborando com os dados obtidos nas curvas de viscosidade anteriormente apresentadas (Figuras 1 e 2). Ao longo do tempo, se observa uma redução na viscosidade das amostras, com as maiores reduções relativas em IC1 (13\%), IC2 (11,5\%) e IC3 (10\%), nesta ordem, em coerência com os valores calculados para histerese (Tabela 4), que também decresceram nesta sequência

A Tabela 8 apresenta os resultados dos testes de tixotropia ajustados ao modelo de Weltman.

O parâmetro A indica a resistência ao escoamento, tendo forte correlação com o limite de escoamento, se relacionando com a tensão de cisalhante no tempo $1 \mathrm{~s}$. Observa-se que os valores do parâmetro A são coerentes com os valores de $\tau_{0}$ (Tabela 6), com exceção da amostra IC3, na qual há uma mudança de ordem de grandeza entre os parâmetros.

Gonçalvez et al. (2005) avaliaram o comportamento reológico de iogurtes com diferentes concentrações de amido e gelatina como espessantes, bem como de iogurte sem espessante. Obtiveram valores do

Tabela 7. Parâmetros do modelo de Herschel-Bulkley para as amostras de iogurte.

\begin{tabular}{cccc} 
Amostras & \multicolumn{3}{c}{ Curva de fluxo (ascendentes) } \\
& $\tau_{\mathbf{0}} \mathbf{( P a )}$ & $\mathbf{K}\left(\mathbf{P a} \cdot \mathbf{s}^{\mathbf{n}}\right)$ & $\mathbf{n}$ \\
IC1 & 16,58 & 19,58 & 0,08 \\
IC2 & 1,34 & 0,28 & 0,69 \\
IC3 & 2,07 & 0,82 & 0,51 \\
\hline
\end{tabular}

parâmetro A entre 46 e 124, maiores que os obtidos para as amostras de iogurtes comerciais que utilizaram outros tipos de espessantes em sua formulação (goma alfarroba, goma xantana, goma guar, goma carragena e carboximetilcelulose).

O parâmetro B mede a velocidade em que ocorre o dano estrutural quando o fluido é submetido a alguma taxa de cisalhamento. Os valores negativos indicam a diminuição da tensão em função do aumento da taxa cisalhante. Verifica-se que a amostra IC1 apresentou a maior taxa de quebra estrutural em valor absoluto, condizente com o maior cálculo de histerese para esta amostra, indicando maiores danos estruturais.

As curvas da viscosidade em função da temperatura estão dispostas na Figura 4. Foram realizados os ajustes das curvas ao modelo de Arrhenius na forma linearizada, sendo o parâmetro de ajuste $\left(\eta_{0}\right)$ e a energia de ativação para viscosidade (E) determinados como o coeficiente linear e o coeficiente angular das curvas, respectivamente. Estes parâmetros e o coeficiente de regressão $r^{2}$ referentes às curvas da Figura 4 são apresentados na Tabela 9.

A curva da amostra IC3 não foi bem representada pela equação de Arrhenius, visto que o coeficiente $r^{2}$

Tabela 8. Parâmetros do modelo de Weltman para os testes de tixotropia.

\begin{tabular}{crcc} 
Amostras & \multicolumn{3}{c}{ Parâmetros } \\
IC1 & \multicolumn{1}{c}{ A } & B & $\boldsymbol{r}^{2}$ \\
IC2 & 13,27 & $-1,06$ & 0,9226 \\
IC3 & 8,51 & $-0,64$ & 0,9743 \\
\hline
\end{tabular}

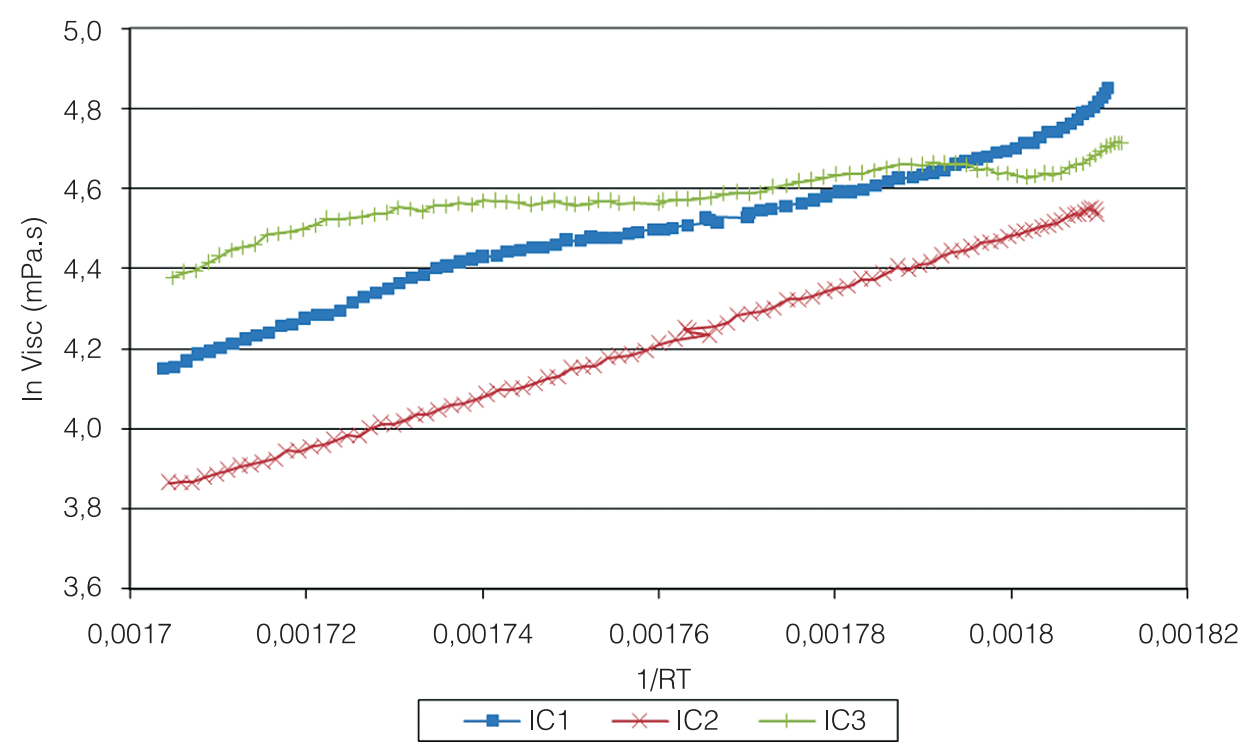

Figura 4. Efeito da temperatura sobre a viscosidade das amostras de iogurte. [IC1 (Goma alfarroba), IC2 (Goma xantana e Goma guar), IC3 (Carboximetilcelulose, Goma carragena e Goma xantana)]. 
Avaliação do comportamento reológico de diferentes iogurtes comerciais

MATHIAS, T. R. S. et al.

Tabela 9. Parâmetros da Equação de Arrhenius calculados para as diferentes amostras de iogurte.

\begin{tabular}{cccc} 
Amostras & $\eta_{\mathbf{0}}$ (mPa.s) & $\mathbf{E}(\mathbf{k c a l} / \mathbf{m o l})$ & $\boldsymbol{r}^{\mathbf{2}}$ \\
IC1 & 5,18 & 5,50 & 0,9800 \\
IC2 & 7,47 & 6,64 & 0,9990 \\
IC3 & 0,79 & 2,15 & 0,8890 \\
\hline
\end{tabular}

foi menor que 0,9. Por outro lado, as demais curvas se apresentam bem ajustadas pelo modelo $\left(r^{2}>0,9\right)$. A energia de ativação variou entre 2,15 e 6,64 kcal/mol; os maiores valores, muito próximos, foram determinados para as amostras IC2 e IC1. A amostra IC2 apresentou o melhor ajuste ao modelo $\left(r^{2}=0,999\right)$.

Os valores da energia de ativação indicam a sensibilidade da viscosidade em função da variação de temperatura; quanto maior o valor de $E$, mais sensível é o produto a alterações reológicas (STEFFE, 1996). Dessa forma, observa-se que a utilização da goma alfarroba como espessante (amostra IC1), apesar de aumentar a viscosidade do produto, pode tê-lo tornado mais propensa a danos na estrutura em razão de oscilações de temperatura. A amostra IC2 (Goma xantana e Goma guar) foi a mais susceptível aos danos estruturais em função da atuação da temperatura.

\section{Conclusões}

Todas as amostras de iogurte apresentaram comportamento não newtoniano pseudoplástico e tixotrópico. As três marcas comerciais apresentaram diferentes faixas de viscosidade em função da taxa de cisalhamento. O iogurte que utiliza goma alfarroba como espessante apresentou os maiores valores de viscosidade e histerese. O modelo de Herschel-Bulkley apresentou a melhor adequação às curvas de fluxo e viscosidade ( $r>0,99)$ e confirmou a característica pseudoplástica para as três amostras de iogurte avaliadas. Os parâmetros consistência $(K)$ e limite de escoamento $\left(\tau_{0}\right)$ tiveram maiores valores para a amostra que emprega goma alfarroba como agente espessante, coerentes com os resultados de viscosidade. A amostra de iogurte IC1 apresentou a maior velocidade de quebra estrutural sob cisalhamento. A amostra IC2 (Goma xantana e Goma guar) foi a mais susceptível aos danos estruturais em razão das oscilações de temperatura. Conclui-se que os diferentes espessantes empregados na produção dos iogurtes influenciaram a viscosidade e a consistência do produto final.

\section{Referências}

BRASIL. Ministério da Agricultura, Pecuária e Abastecimento. Resolução $n^{\circ}$ 5, de 13 de novembro de 2000. Padrões de Identidade e Qualidade de Leites Fermentados. Diário Oficial da República Federativa do Brasil, 02 jan. 2001. Seção 1, p. 75-78.

CHANDAN, R. C.; WHITE, C. H.; KILARA, A.; HUI, Y. H. Manufacturing Yogurt and Fermented Milks. London: Blackwell Publishing Ltd., 2006. 364 p. http://dx.doi. org/10.1002/9780470277812

COLLET, L. S. F. C. A.; TADINI, C. C. Sodium caseinate addition effect on the thixotropy of stirred yogurt. In: INTERNATIONAL CONFERENCE ON ENGINEERING AND FOOD, 9., 2004, Montpellier. Annals... Montpellier: ICEF, 2004. p. 317-322.

CUNHA NETO, O. C.; OLIVEIRA, C. A. F.; HOTTA, R. M.; SOBRAL, P. J. A. Avaliação físico-química e sensorial do iogurte natural produzido com leite de búfala contendo diferentes níveis de gordura. Ciência e Tecnologia de Alimentos, Campinas, v. 25, n. 3, p. 448-453, 2005. http://dx.doi.org/10.1590/S010120612005000300010

DRAKE, M. A. Sensory analysis of dairy foods. Journal of Dairy Science, Champaign, n. 90, p. 4925-4937, 2007.

FOOD INGREDIENTS BRASIL - FiB. Estabilizantes. Food Ingredients Brasil, Barueri, n. 14, p. 42-48, 2010.

GOMES, R. G.; PENNA, A. L. B. Características reológicas e sensoriais de bebidas lácteas funcionais. Semina: Ciências Agrárias, Londrina, v. 30, n. 3, p. 629-646, 2009.

GONÇALVES, A.; EBERLE, I. Frozen yogurt com bactérias probióticas. Alimentos e Nutrição, Araraquara, v. 19, n. 3, p. 291-297, 2008

GONÇALVEZ, D.; PÉREZ, C.; REOLON, G.; SEGURA, N.; LEMA, P.; GÁMBARO, A.; ARES, G.; VARELA, P. Effect of thickeners on the texture of stirred yogurt. Alimentos e Nutrição, Araraquara, v. 16, n. 3, p. 207-211, 2005.

HOLDSWORTH, S. D. Rheological models used for the prediction of the flow properties of food products: a literature review. Transactions of the Institution of Chemical Enginners, London, v. 71, part C, p. 139-179, 1993.

HORNE, D. S. Casein interactions: casting light on the Black Boxes, the structure in dairy products. International Dairy Journal, Barking, v. 8, n. 3, p. 171-177, 1998. http://dx.doi. org/10.1016/S0958-6946(98)00040-5

LEE, W. J.; LUCEY, J. A. Formation and physical properties of yogurt. Asian-Australasian Journal of Animal Sciences, Seoul, v. 23, n. 9, p. 1127-1136, 2010. http://dx.doi.org/10.5713/ ajas.2010.r.05

LUCEY, J. A. Formation and physical properties of milk protein gels. Journal of Dairy Science, Champaign, v. 85 , n. 2, p. 281-294, 2002. http://dx.doi.org/10.3168/jds.S00220302(02)74078-2

MULLINEUX, G.; SIMMONS, M. J. H. Effects of processing on shear rate of yoghurt. Journal of Food Engineering, Oxford, 
Avaliação do comportamento reológico de diferentes iogurtes comerciais

MATHIAS, T. R. S. et al.

v. 79, n. 3, p. 850-857. 2007. http://dx.doi.org/10.1016/j. jfoodeng.2006.03.005

OLIVEIRA, K. H.; SOUZA, J. A. R.; MONTEIRO, A. R. Caracterização reológica de sorvetes. Ciência e Tecnologia de Alimentos, Campinas, v. 28, n. 3, p. 592-598, 2008. http:// dx.doi.org/10.1590/S0101-20612008000300014

PASEEPHOL, T.; SMALL, D. M.; SHERKAT, F. Rheology and texture of set yogurt as affected by inulin addition. Journal of Texture Studies, Malden, v. 39, n. 6, p. 617-634. 2008. http:// dx.doi.org/10.1111/j.1745-4603.2008.00161.x

RASIC, J. L.; KURMANN, J. A. Yoghurt: Scientific Grounds Technology, Manufacture \& Preparation. Copenhagen: Technical Dairy Publishing House, 1978. 427 p.

ROBINSON, R. K.; LUCEY, J. A.; TAMIME, A. Y. Manufacture of Yoghurt. In: TAMIME, A. Y. (Ed.). Fermented Milks. Oxford: Blackwell Science Ltd., 2006. cap. 3, p. 53-75.

SCHRAMM, G. Reologia e Reometria - Fundamentos Teóricos

e Práticos. São Paulo: Editora Artliber Ltda., 2006. 240 p.
SODINI, I.; JOHN, M.; TONG, P. S. Physical properties of yogurt fortified with various commercial whey protein concentrates. Journal of the Science of Food and Agriculture, Malden, v. 85 , n. 5, p. 853-859, 2005. http://dx.doi.org/10.1002/jsfa.2037 STEFFE, J. F. Rheological methods in food process engineering. 2nd ed. Freeman Press: Michigan, 1996. 418 p.

TAMIME, A. Y.; ROBINSON, R. K. Yogurt: Ciencia y Tecnologia. Zaragoza: Acribia, 1991. 368 p.

TELES, C. D.; FLÔRES, S. H. Influência da adição de espessantes e leite em pó nas características reológicas do iogurte desnatado. Boletim do CEPPA, Curitiba, v. 25, n. 2, p. 247-256, 2007.

TONELI, J. T. C. L.; MURR, F. E. X.; PARK, K. J. Review: Estudo da reologia de polissacarídeos utilizados na indústria de alimentos. Revista Brasileira de Produtos Agroindustriais, Campina Grande, v. 7, n. 2, p. 181-204, 2005.

WALSTRA, P.; WOUTERS, J. T. M.; GEURTS, T. J. Dairy Science and Technology. 2nd ed. Netherlands: CRC Press, 2006. 808 p. 